\title{
Decision support system integrating GIS with simulation and optimisation for a biofuel supply chain
}

\author{
Fengli Zhang $^{\mathrm{a}}$, Dana Johnson ${ }^{\mathrm{b}}$, Mark Johnson ${ }^{\mathrm{c}}$, David Watkins ${ }^{\mathrm{d}}$, Robert Froese ${ }^{\mathrm{e}}$, Jinjiang Wang ${ }^{\mathrm{a}}{ }^{*}$ \\ ${ }^{a}$ College of Mechanical and Transportation Engineering, China University of Petroleum, Beijing, 102249, China \\ ${ }^{b}$ School of Business and Economics, Michigan Technological University, Houghton, MI 49931, USA \\ ${ }^{c}$ School of Technology, Michigan Technological University, Houghton, MI 49931, USA \\ ${ }^{d}$ Dept. of Civil and Environmental Engineering, Michigan Technological University, Houghton, MI 49931, USA \\ ${ }^{e}$ School of Forest Resources and Environmental Science, Michigan Technological University, Houghton, MI \\ 49931,USA
}

\section{Abstract}

A range of economic and societal issues has resulted from fossil fuel consumption in the transportation sector in the U.S. These include health related air pollution, climate change, dependence on imported oil, and other oil related national security concerns. Biofuels production from various lignocellulosic biomass types, such as wood, forest residues, and agriculture residues, have the potential to replace a portion of the total fossil fuel consumption. This study focused on locating biofuel facilities and designing the biofuel supply chain to minimise the overall cost. For this purpose, an integrated methodology was proposed by combining the Geographic Information System technology with simulation and optimisation modelling methods. The GIS-based method was used as a precursor for selecting biofuel facility locations by employing a series of decision factors. The identified candidate sites for biofuel production served as inputs for simulation and optimisation modelling. The simulation/optimisation model and identified locations provided an integrated decision support system for decision makers to determine the optimal cost, energy consumption, and emissions for candidate locations. This novel methodology development extends prior research.

\section{Keywords}

Biofuel; woody biomass; supply chain; multiple criteria analysis

\section{Introduction}

A range of societal issues have been caused by fossil fuel consumption in the transportation sector in the U.S., including health related air pollution, climate change, dependence on imported oil, and other oil related national security concerns [1]. Biofuels production from various forms of lignocellulosic, biomass materials such as wood, forest residues, and agriculture residues have the potential to replace a portion of the total fossil fuel consumption [2]. This study focused on locating biofuel facilities and designing the biofuel supply chain to minimise the overall cost. For this purpose an integrated methodology was proposed by combining the Geographic Information System (GIS) technology with simulation and optimisation modelling methods. The GIS-based method was used as a precursor for selecting biofuel facility locations by employing a series of decision factors. The identified candidate sites for biofuel production served as inputs for simulation and optimisation modelling.

There is a stream of literature on modelling biofuel supply chains and facility location problems by using one of the three modelling approaches or by combining two of the methods. However, literature on the integrated approach by combining all three methods is less extensive. GIS has proved to be an effective tool to address issues related to biofuel facility location selection, biomass availability, and biomass logistics [3-6]. Simulation models had been

\footnotetext{
* Corresponding author. Tel.: +86-13552996406. Email address: jwang@ cup.edu.cn
} 
developed to track flows of a given supply chain network [7]. For example, the integrated biomass supply analysis and logistics model (IBSAL) for supplying corn stover to a biorefinery [8-9]; and the Straw Handling Model (SHAM) built for delivering straw to a heating plant [1011]. The optimisation modelling method had been widely used for biofuel supply chain design [12-17]. Walther et al. [18] built a multi-period MIP-model for integrated location, capacity and technology planning for the design of production networks for second generation biodiesel. Dekker et al. [19] presented a review that highlights the contribution of Operations Research (OR) to green logistics, focusing on design, planning and control in a supply chain for transportation, inventory of products and facility decisions.

Simulation combined with optimisation was demonstrated to be an effective method to identify the optimal combination of biomass feedstock type, transportation mode, and number of biorefineries before actual plant construction [20]. Two studies, Elia et al. [20] and Leduc et al. [21] used simulation results as input for optimisation modelling to evaluate biofuel production. Elia et al. [20] built a MILP formulation to assess hybrid coal, biomass, and natural gas supply network for liquid biofuel production in the U.S. A total of 270 simulation runs were conducted for various combinations of feedstock types (e.g. biomass, natural gas and coal) and biorefinery capacities. The simulation results, such as the to-be-delivered amount of feedstock to a plant and the amount of biofuel produced, were used as input for the MILP model and the optimal supply network was determined [20]. Leduc et al. [21] developed a simulation-based optimisation model to evaluate combined ethanol, power, heat, and biogas production in Sweden. The simulation results were used as inputs for the optimisation model in terms of yields of ethanol, electricity, heat and biogas produced from biomass feedstock [21]. The optimal location of building an ethanol facility was identified and the ethanol price was computed [21].

De Mol et al. [22] created both simulation and optimisation models for the logistics of biomass fuel collection. The two models share similarities and also have some differences. The simulation model is preferred when the network structure of the logistics is pre-defined. The optimisation model is more effective to determine the optimal network structure, including the optimal mixture of biomass types [22]. Since the actual transports were determined by the simulation model, it allows for tracking of time-dependent parameters, such as moisture and dry matter losses through the collection network. In optimisation modelling it is difficult to include the time-dependent effects because they are based on the annual flows [22]. The simulation model used cost and energy consumption as performance indicators while the optimisation model determined calculated cost [22].

There is limited work in the area of modelling woody biomass supply chains using optimisation and simulation simultaneously [20-22]. Additionally as a precursor to optimisation or simulation modelling, the GIS-based facility location analysis considers a series of factors simultaneously. To date, we are unaware of the application of these three methods integrated into a single research study. The benefit of integrating all three methods is its capability of addressing several issues that add complexity to the supply chain model, such as biomass harvesting and transport. For northern climates with snow and ice, the spring breakup period imposes weight limits on transportation vehicles. This is because of the thawing and freezing cycle of the roadways in the spring that subject them to damage if heavily travelled by vehicles with full loads. It is not economically viable to travel with partially loaded vehicles. The variability of spring breakup timing introduced uncertainties into the supply chain. The simulation model was designed to focus on these uncertainties. The spring break-up time could be specified as scenarios input to each harvest area in order to allow representation of the time dynamics of the 
system [23]. The simulation model could show how the given supply system works during the spring breakup.

\section{Integrated methodology}

95

The proposed integrated methodology, that combines the GIS technology with simulation and optimisation modelling methods, is illustrated in Fig. 1. The GIS-based methodology was applied as a first step for selecting biofuel facility locations by employing a series of decision factors to include accessibility to biomass, railway/road transportation network, water body, and workforce. The resulting candidate sites served as inputs for the simulation and optimisation modelling. Using additional data including biomass availability, cost factors, energy factors, and emissions factors, the simulation model tracks flows of a given supply chain network, whilst the optimisation model identifies the optimal supply chain network. Both models can be applied to determine the optimal cost, consisting of the delivered feedstock cost, inventory holding cost, energy consumption cost, and GHG emissions cost for candidate locations.

Whilst the simulation model provided detailed outputs for specified scenarios, strategic questions such as how many harvesting areas should be included, when and where to acquire harvesting contracts, and what is the operating plan for spring breakup were addressed by simulating multiple scenarios over multiple years. The optimisation model was developed to inform these strategic decisions. The annual optimisation results were disaggregated and synchronized with the required weekly simulation input. After several replications (or several years) of a simulation run, the simulation model showed statistical results for the outputs. The simulation outputs provided feedback to the optimisation model in the form of refined parameter values. The optimisation model was then run again to provide updated strategic plans to the simulation model. This process can be repeated as necessary in order to develop a robust solution to the scenario being considered.

Fig. 1 NEAR HERE

\subsection{GIS-based methodology for preselecting biofuel facility locations} As a precursor to simulation or optimisation modelling, the GIS-based methodology was used to preselect potential biofuel facility locations for biofuel production from forest biomass. Fig. 2 presents an overview of the GIS-based methodology, which considered eight decision factors [7]: (a) county boundaries, (b) a railroad transportation network, (c) a state/federal road transportation network, (d) water body (rivers, lakes, etc.) dispersion, (e) city and village dispersion, (f) a population census, (g) biomass production, and (h) location of co-fired power plants. As a siting determinant, population census was chosen to ensure labour availability for a biofuel facility. A biofuel facility should be situated close to water distribution in order to minimise variable operating expenses [24]. Cities or villages having an existing or proposed biomass co-fired power plant were excluded due to the possibility of competition for biomass feedstock.

\subsection{Mathematical model}

Fig. 2 NEAR HERE

130 A mixed integer linear program (MILP) model was developed to design a biomass-to-biofuel supply chain and manage the logistics of a biorefinery. System modelling of the biofuel supply chain consists of two layers: harvesting areas and potential locations for biorefineries. The objective function was to minimise the total biofuel supply chain system cost. The model aimed to identify the number, size and location of biorefineries needed to process the biomass availability in a particular region. The amount of biomass to be transported between the two 
layers, on an annual basis, was also determined. The notation of the model is summarized in the

137 Appendix.

\section{$138 \quad \mathbf{2 . 2 . 1}$ Inventory quantity and cost}

139 For biomass processing, the planning of onsite storage becomes necessary in order to provide enough biomass feedstock to get through periods where road weight restrictions are in place. For example, for northern climates with snow and ice, roads are weight restricted during the period of spring breakup [25]. This requires careful planning of harvesting and transport operations to meet not only the daily demand but also additional biomass to build up extra inventory.

Fig. 3 shows how the on-hand availability of stored biomass may be built and then used during the time period where roads are weight restricted. The inventory can be determined by the spring breakup duration $\left(\mathrm{T}_{\mathrm{sb}}\right)$, daily feedstock demand $\left(\mathrm{DD}_{\mathrm{j}}\right)$ at a biorefinery, and the time it takes to build inventory $\left(\mathrm{T}_{\mathrm{bi}}\right)$ [25]. However, Zhang et al. [25] did not consider a minimum onhand inventory, which is required to ensure continuous production in facility. The minimal inventory can be set as proportional to the annual biomass requirement [26]. As shown in Fig. 3 the overall inventory over a year equals the sum of the area of the rectangle (representing minimum on-hand inventory) and the area of the triangle (representing spring breakup inventory). Thus the average inventory level of biomass over a year $b_{\text {inv }}$ (tonnes/year) is calculated as

$$
b_{i n v}=n \cdot D D_{j}+\frac{T_{s b} \cdot D D_{j} \cdot\left(T_{b i}+T_{s b}\right)}{2 \times 365}
$$

where $\mathrm{n}$ is the number of operation days that the minimum on-hand inventory can meet, $\mathrm{DD}_{\mathrm{j}}$ is the daily biomass demand, $\mathrm{T}_{\mathrm{sb}}$ is the duration of spring breakup (days), and $\mathrm{T}_{\mathrm{bi}}$ is the time required to build inventory prior to spring breakup (days). The daily biomass demand $\mathrm{DD}_{\mathrm{j}}$ (tonnes/day) for a biofuel facility with a size $\mathrm{s}_{\mathrm{j}}$ (MLPY, million litres per year) is calculated as

$$
D D_{j}=\frac{s_{j} \cdot 10^{6}}{r \cdot N}
$$

where $\mathrm{r}$ is conversion rate (litres biofuel per green tonne of biomass) and $\mathrm{N}$ is the number of operation days. Thus, with a unit inventory holding cost $\mathrm{H}$ (\$/tonne-year), the annual inventory holding cost $\left(c_{j}^{i n v}, \$\right)$ is calculated as:

$$
c_{j}^{i n v}=b_{i n v} \cdot H
$$

\subsubsection{Modelling multi-biorefinery problem}

For the multiple biofuel facilities scenario, a MILP model was formulated and implemented. The solution to the MILP model represents decisions regarding (1) the optimal number, locations, and sizes of the biofuel facilities to meet a certain demand for biofuel, and (2) the amounts of biomass to be transported between the harvesting areas and the biofuel facilities over a selected period, and minimise the sum of the delivered feedstock cost, inventory holding cost, energy consumption cost and GHG emissions cost. The three measures used to characterize the supply system performance are cost, energy consumption, and GHG emissions. Since the three performance indicators are in different units of measure, the amount of energy consumption and GHG emissions were converted into monetary value. The objective is to minimise the total biofuel supply chain system cost C (Eq. 4) that is the sum of the delivered feedstock cost, inventory holding cost, energy consumption cost and GHG emissions cost. The model can be stated as follows: 
Minimise $C=c_{i j}+c_{j}^{i n v}+e_{i j} \cdot \alpha+g_{i j} \cdot \beta$

where

$$
\begin{array}{ll} 
& c_{i j}=\sum_{j=1}^{J} \sum_{i=1}^{I}\left(s+h+t_{l u}+t_{d} \cdot d_{i j}\right) \cdot q_{i j} \\
& e_{i j}=\sum_{j=1}^{J} \sum_{i=1}^{I}\left(e_{h}+e_{t r} \cdot d_{i j}\right) \cdot q_{i j} \\
& g_{i j}=\sum_{j=1}^{J} \sum_{i=1}^{I}\left(g_{h}+g_{t r} \cdot d_{i j}\right) \cdot q_{i j} \\
\text { s.t. } \quad & \sum_{j=1}^{J} q_{i j} \leq b_{i} \forall i \\
& \sum_{i=1}^{I} q_{i j}=10^{6} \cdot s_{j} / r \forall j \\
& \sum_{j=1}^{J} s_{j}=D
\end{array}
$$

The minimised average cost is calculated based on the minimised total cost and the total amount of biomass transported on an annual basis as follows.

$$
c_{a v g}=C / \sum_{j=1}^{J} \sum_{i=1}^{I} q_{i j}
$$

The cost component $c_{i j}$ (Eq. 5) is a sum of stumpage cost, harvesting/forwarding cost, and transportation cost. The stumpage cost is the payment made to landowners. The transportation cost consists of two major terms: loading and unloading cost (distance-independent cost) and variable cost (distance-dependent cost). In terms of the processes that deliver biomass to a processing facility, energy consumption and GHG emissions are assumed to be associated with harvesting/forwarding and transportation activities only. Since the inventory is assumed to be stored at the biofuel facility the energy consumption and GHG emissions of moving inventory is not included. The energy component $e_{i j}$ (Eq. 6) is a sum of energy consumed during biomass harvesting/forwarding and transportation. The emissions component $g_{i j}$ (Eq. 7) is a sum of emissions associated with biomass harvesting/forwarding and transportation.

Constraint (8) ensures that the delivered amount of biomass from harvesting area $i$ do not exceed its corresponding maximum availability, while constraint (9) ensures that the demand for biomass of a biofuel facility at location $j$ equals supply. Constraint (10) ensures the biofuel production meets the annual biofuel demand. The lower and upper bounds of facility size are 
enforced in constraint (11). Nonnegative variables of the amount (tonnes) of biomass transported from harvesting area $i$ to biofuel facility $j$ are described as constraint (12), while constraint (13) enforces the binary nature of the decision variables $\varphi_{j}$.

\subsubsection{Modelling single biorefinery problem}

The single biorefinery problem is a specific example of the multi-biorefinery problem when the location of the biorefinery is known and the size is constant. The objective function is minimising the total biofuel supply chain system cost (C) which is the sum of the delivered feedstock cost, inventory holding cost, energy consumption cost and GHG emissions cost. The constraints and limitations are the same except that the location of the biorefinery is known and the size is constant. Therefore, in this case the parameter $\varphi_{j}$ equals 1.

\section{Case study area}

The integrated method has been evaluated by considering the locations of biofuel facilities in the northern part of Michigan's Lower Peninsula (NLP). The State of Michigan, especially the northern portion, has a large biomass resource base which could be used as feedstock for biofuel facilities. More than half (54\%) of Michigan's land area is covered by forests [27]. Out of this, $38 \%$ of the total timberland is located in the NLP [28]. The annual growth of wood in Michigan is 21.7 million cubic metres of live trees. Out of this, 10.8 million cubic metres is removed each year, leaving an unutilized resource of approximately 10.9 million cubic metres per year [27]. The growth to removals ratio $(\mathrm{G} / \mathrm{R})$ is calculated as 2.0 , which is a common measure of forest sustainability. The NLP has a high annual net growth at 9.08 million cubic metres of live trees [28].

\subsection{Data collection}

\subsubsection{Data required for GIS analysis}

Data required for GIS analysis, including county boundaries of the L.P., the railroad transportation network, the state/federal road transportation network, water body dispersion, and city and village locations in the L.P., was retrieved from the Michigan Geographic Data Library [29]. The transportation distances were calculated using the rectilinear distance for latitude and longitude of the centroid for each of the counties within a $161 \mathrm{~km}$ radius of the specific location and the selected biorefinery location. Michigan census data was obtained from the U.S. Census Bureau. The census data for all cities and villages in the L.P. in 2006 was integrated into a GIS data layer.

County-based biomass data was collected from the Forest Service Inventory EVALIDator web application version 4.01 [30]. Forest biomass, defined here as roundwood pulpwood that can be harvested and collected with forestry equipment commonly used in Michigan, were used as feedstock for this perspective of study. Three types of ownership were defined: federal forests (national), state forests, and private landowner, including corporations. The species are aggregated by soft and hard wood but are not separated in any greater detail. Adjustment was made for the quantities for known, planned uses of forest biomass. This includes an adjustment of hardwood information for overlapping counties for the planned biorefinery facility in Kinross, Chippewa County in the Upper Peninsula (U.P.) of Michigan [31].

\subsubsection{Cost factors}

The cost factors associated with biomass stumpage cost paid to landowners, harvesting/forwarding, truck transportation, and inventory holding were collected. The stumpage cost made to landowners is assumed to be $\$ 10.36 /$ tonne and the harvesting/forwarding cost is $\$ 15.44 /$ tonne [32]. The loading and unloading cost for truck transportation is calculated as $\$ 4.10 /$ tonne and the variable cost is $\$ 0.051 /$ tonne- $\mathrm{km}$ [7]. The inventory holding cost includes 
any expense incurred to maintain an inventory of biomass at the biorefinery. The unit inventory holding cost is assumed to be $\$ 8.88 /$ dry tonne per week [13]. Based on the assumption of a green tonne containing roughly $50 \%$ moisture, the unit inventory holding cost is calculated as $\$ 4.44$ per green tonne per week. Since the length of a time period in this study is one year, the annual inventory holding cost is calculated as $\$ 230.88$ per tonne per year $(\$ 4.44 /$ tonne-week $* 52$ weeks/year $=\$ 230.88 /$ tonne-year). The U.S. Energy Information Administration [33] provides historical data of the diesel fuel prices. A five-year average diesel fuel price was calculated as $\$ 0.91 / \mathrm{L}$ using historical data between 2008 and 2012. The diesel fuel price was converted to $\$ 0.0225 / \mathrm{MJ}$ with the diesel energy impact factor of $40.5 \mathrm{MJ} / \mathrm{L}$ [34]. The environmental costs per unit of $\mathrm{CO}_{2}$ emissions were estimated as $0.108 \mathrm{EUR} / \mathrm{kg}$ by the EPS 2000 (Environmental Priority Strategies in product design, version 2000) system using the LCA methodology [35-36]. The average exchange rate for the first six months of 2007 is $1 \mathrm{EUR}=1.329$ U.S. dollar [37]. Thus the environmental costs per unit of $\mathrm{CO}_{2}$ emissions were converted to $\$ 0.144 / \mathrm{kg}$. Since $\mathrm{CO}_{2}$ is the primary GHG emitted through transportation activities, the environmental costs per unit of $\mathrm{CO}_{2}$ emissions is taken as the environmental costs per unit of GHG emissions. Table 1 provides a summary of the input data used.

\subsubsection{Energy and emissions factors}

Energy and emissions factors associated with biomass harvesting/forwarding, and transportation were calculated using the assumptions and literature values (Table 2). In both supply chain stages (harvesting/forwarding and transportation), diesel fuel use was the primary driver of environmental burdens. Forest feedstock production was assumed to take place with a full processor and forwarder equipment configuration. Truck transportation was assumed using Michigan log trucks which are typically "truck + trailer" units capable of hauling much larger loads (40 - 45 tonnes average assumed) than is typical in neighbouring states [38]. Energy demand factors and emissions factors have been normalized to one tonne of biomass production, assumed to be a green tonne containing roughly $50 \%$ moisture. GHG emissions associated with machine construction, maintenance and replacing capital equipment are also included. Note that the factor values associated with truck transportation activity are estimated based on round trips.

\subsection{Model assumptions}

Table 2 NEAR HERE

A series of assumptions were presented to simplify the supply chain [7]. Additional assumptions are as follows.

$>$ Biofuel facility

- A 189 MLPY biofuel facility would use an estimated 1,133,750 green tonnes of biomass per year with a conversion factor of 167 litres of biofuel per green tonne of biomass [39];

- A 151 MLPY biofuel facility would use about 907,000 green tonnes of biomass per year;

- A 114 MLPY biofuel facility would use about 680,250 green tonnes of biomass per year; and

- A beginning inventory that can meet five-day demand for biomass feedstock at a biofuel facility is set up for the start of the year. For a 189 MLPY biofuel facility, 22,675 tonnes (500 truckloads) of beginning inventory is required [7]. For a 151 MLPY biofuel facility, the beginning inventory is 18,140 tonnes (400 truckloads); and for a 114 MLPY biofuel facility, the beginning inventory is 13,605 tonnes (300 truckloads). Inventory will carry over for the rest of the 19 years in each simulation.

Transportation 


\subsection{Total and average costs}

\section{Simulation results}

The start date for the simulation was specified as Nov $1^{\text {st }}, 2013$ and the model run length was 350 days a year, 20 years in total. The time step during the simulation was set as one day. The main outcomes are discussed as follows.

\subsection{Numbers of truckloads per day}

The numbers of truckloads of biomass feedstock required to be transported each day are calculated for different sizes (114 MLPY, 151 MLPY and 189 MLPY) of biofuel facility in the three different time periods. A summary of the number of truckloads per day is presented in Table 3.

\subsection{Inventory level and harvesting areas}

Table 3 NEAR HERE

For example, using one simulation run for a biofuel facility of 189 MLPY in the city of Clare, Michigan, the inventory (tonnes) changes as a function of time following the pattern demonstrated in Fig. 4. The inventory for the first two years' operation is shown in Fig. 5. From the graphs, it can be observed that there are three phases in each year. For the first four months (from Nov till end of February), 112\% more biomass is transported each day than the daily demand to build up the inventory. Starting with March $1^{\text {st }}$, the spring thaw starts and no biomass is transported. Biomass is pulled from the onsite inventory only. When the spring breakup ends at the end of April, a regular operation plan (daily demand is met by daily transportation) is executed. It is clear to see that the inventory levels out during regular operation period. Ten harvesting areas in Table 4 were identified as the most preferable suppliers for supporting the Clare plant.

A series of simulations were run for each of the nine potential biofuel facility locations. The total costs $(\$)$ and the average costs (\$/tonne) were calculated for each different facility locations and sizes (114 MLPY, 151 MLPY and 189 MLPY). The results are shown in Table 5. Based on the total cost and the average cost measurements, it is apparent that Gaylord is the optimal facility location regardless of plant size. This was confirmed by the fact that Gaylord is at the centre of the biomass in the NLP, Michigan. Traverse City is the least favourable location to build a biofuel facility producing 151 or 189 million litres of biofuel per year, while Boyne City is the least favourable location for a 114 MLPY biofuel facility. Among the three different facility sizes at one location, a 114 MLPY biofuel facility was the optimal due to the lowest total cost and average cost. 


\section{Optimisation results}

Table 5 NEAR HERE

The model was implemented using Mathematical Programming Language (MPL) software with the CPLEX solver, which is available from Maximal Software (MAXIMAL 2013, http://www.maximalsoftware.com/mpl/). The input and output data are managed through a Microsoft Excel database. The problem was solved within a few minutes on a PC Intel(R) Core(TM) i3-2357M 1.30 GHz processor.

\subsection{Base Case}

The optimisation model was executed by changing the demand from 189 MLPY to 1,135 MLPY in increments of 189 MLPY. The optimal locations and plant sizes were identified as shown in Table 6. A Gaylord facility may be built to minimise the total biofuel supply chain system cost when the annual biofuel demand is 189 MLPY. This confirmed the results concluded from the simulation model when a biofuel facility of $50 \mathrm{MGY}$ is built in the study area. When the annual demand increased to 379 MLPY, three biofuel facilities may be built at Manton, Gaylord, and West Branch to meet the demand. The optimal plant size is 132 MLPY, 114 MLPY, and 133 MLPY respectively. When the biofuel demand reaches 570 MLPY, five 114 MLPY biofuel facilities may be built at Manton, Kalkaska, Gaylord, Clare, and West Branch. When the demand reaches 1,135 MLPY, seven biofuel facilities need to be built. The optimal plant size is 189 MLPY at Manton, Kingsley, Clare, and West Branch, 149 MLPY at Roscommon, 116 MLPY at Gaylord, and 114 MLPY at Boyne City. As observed from Table 6, Gaylord shows up as one of the optimal candidate locations no matter what the demand is. The results were confirmed by the fact that Gaylord is at the centre of the biomass in the NLP, Michigan.

Table 6 NEAR HERE

\subsection{Comparison analysis and discussion}

A comparison analysis was conducted for multi-location and single location problems when demand varied from 379 MLPY to 1,135 MLPY in increments of 189 MLPY. The geographic locations of the biofuel facilities were identified and total and average costs were calculated. The four components of the overall cost were also estimated, including delivered feedstock cost, inventory holding cost, energy cost, and emissions cost. Finally, the average transportation distance was also calculated.

\subsubsection{Multi-location comparison}

The comparison analysis results for the multi-location problem are shown in Table 7. The delivered feedstock cost and overall cost rise dramatically as the annual biofuel demand increases. This is because a larger scale biofuel facility requires more feedstock transported over longer distances, as shown by the average transportation distance in Table 7. The other component costs, including inventory cost, energy cost, and emissions cost, grows gradually as the annual biofuel demand increased. The average cost increases slightly as the annual biofuel demand rises.

\subsubsection{Single location comparison}

\section{Table 7 NEAR HERE}

Results for single location comparison analysis are shown in Table 8, which follow the same patterns as observed in the multiple locations problem. The delivered feedstock cost and overall cost rises dramatically as the annual biofuel demand increases. This is because a single larger scale biofuel facility requires even more feedstock to be transported over longer distances than with multiple locations. The other component costs, including inventory cost, energy cost, and 
emissions cost, increase gradually as the annual biofuel demand increases, and the average cost increases slightly as the annual biofuel demand rises.

\section{Summary and conclusions}

Table 8 NEAR HERE

This research combines GIS technology with simulation and optimisation modelling methods to successfully characterize the process of supplying biofuel facilities with the goal of minimising the cost of supplying the required biomass. This is a unique combination of three methods that has not been applied to date based on extensive reviews of the literature and represents a significant contribution to the stream of research in this area. In considering the development of a profitable biofuel facility that can sustainably produce biofuel there are two principal questions: i) is there sufficient biomass to sustainably support the needs of a biofuel facility, and ii) what is the best system to gather, handle, and transport the biomass to the biofuel facility? The first question could be addressed by a GIS-based method, of which the effectiveness for biomass resources has been proved numerous times in literature. The answer to the second question is critical since the gathering, handling, and transportation costs represent the overwhelming majority of the costs associated with the production of biofuel. This proposed method provides solutions by focusing on developing a model that can be used to establish a feedstock supply chain that can deliver biomass to the production facility in a low cost, reliable, and time-effective manner.

The combined approach was applied to the NLP, Michigan, where there are restrictions placed on hauling heavy loads over many roads during the spring breakup period. The benefit of integrating all three methods is its capability of addressing several issues that add complexity to the supply chain model. One example is the variability of spring break-up timing which introduces uncertainty to the supply chain. The simulation model could specify spring breakup time scenarios input to each harvest area in order to allow representation of the time dynamics of the system [23]. The simulation model shows how the given supply system works during the spring breakup.

The optimal results of multiple locations with predefined supply chains serves as inputs of the simulation model. The model simulates multiple scenarios (nine biofuel facility locations with different plant sizes of 114 MLPY, 151 MLPY or 189 MLPY) over multiple years (20 years) and tracks costs and flows. The Gaylord city is identified to be one of the optimal candidate locations regardless of the plant size and the annual demand (from 189 MLPY to 1,135 MLPY in increments of $189 \mathrm{MLPY}$ ). It was also found that the delivered feedstock cost and overall cost rises dramatically as the demand increases. This is because a larger scale biofuel facility requires more feedstock transported over longer distances. The other component costs, including inventory cost, energy cost, and emissions cost, grew more gradually as the annual biofuel demand increased.

The presented integrated methodology is also applicable for more or less capitalintensive biodiesel plants because the supply chain is essentially the same. The methodology can also be easily applied and is generalizable to other regions in the U.S. With GIS it is relatively easy to add data layers for different regions of the U.S. The optimisation and simulation models can be extended to other locations because of the standardized model inputs.

\section{Appendix: Summary of notation}

Sets and indices

434 - I Set of harvesting sites, indexed by $i$. 
- $J$ Set of potential locations for biofuel facility, indexed by $j$.

Parameters

- $\quad c_{j}^{i n v}$ Annual inventory holding cost at biofuel facility $\mathrm{j}$.

- $c_{i j}$ Delivered feedstock cost (\$/tonne) of biomass, including stumpage cost, harvesting/forwarding cost, and transportation cost.

- $e_{i j}$ Energy consumption (MJ/tonne), associated with harvesting/forwarding and transportation.

- $g_{i j} \mathrm{GHG}$ emissions ( $\mathrm{kg} /$ tonne), associated with harvesting/forwarding and transportation.

- $C$ Total cost that is the sum of the delivered feedstock costs, inventory holding cost, energy consumption cost, and GHG emissions cost.

- $D D_{j}$ Daily demand for biomass feedstock (tonnes/day) at biofuel facility $j$.

- $D R_{j}^{r e}$ Daily received amount of biomass feedstock (tonnes/day) at biofuel facility j per day in regular months from May $1^{\text {st }}$ to Oct $15^{\text {th }} / 16^{\text {th }}$.

- $D R_{j}^{b i}$ Daily received amount of biomass feedstock (tonnes/day) at biofuel facility j per day from Nov $1^{\text {st }}$ to the end of Feb to build up inventory for spring breakup.

- $T D_{j}$ Daily demand for biomass feedstock (truckloads/day) at biofuel facility $j$.

- $T R_{j}^{r e}$ Daily received amount of biomass feedstock (truckloads/day) at biofuel facility $j$ per day in regular months from May $1^{\text {st }}$ to Oct $15^{\text {th }} / 16^{\text {th }}$.

- $T R_{j}^{b i}$ Daily received amount of biomass feedstock (truckloads/day) at biofuel facility $j$ per day from Nov $1^{\text {st }}$ to the end of Feb to build up inventory for spring breakup.

Model inputs

- $b_{i}$ Biomass availability (tonnes/year) at harvesting site $i$.

- $r$ Conversion rate (gallons biofuel /green tonne of biomass).

- $D$ Total biofuel demand (MLPY).

- $s$ Unit stumpage cost (\$/tonne) of biomass, assuming the unit stumpage cost is constant for different harvesting areas.

- $h$ Unit harvesting/forwarding cost (\$/tonne) of biomass, assuming the unit harvesting/forwarding cost is constant for different harvesting areas.

- $\quad H$ Unit inventory holding cost (\$/tonne-year), assuming the unit inventory holding cost is constant for different biofuel facility locations.

- $t_{l u}$ Truck loading and unloading cost (\$/tonne).

- $t_{d}$ Truck variable cost $(\$ /$ tonne-km).

- $e_{h}$ Energy use (MJ/tonne) of harvesting / forwarding feedstock.

- $e_{t r}$ Energy use (MJ/tonne-km) of truck transportation.

- $g_{h} \mathrm{GHG}$ emissions (kg/tonne) of harvesting / forwarding feedstock.

- $g_{t r}$ GHG emissions ( $\left.\mathrm{kg} / \mathrm{tonne}-\mathrm{km}\right)$ of truck transportation.

- $\alpha$ Energy cost per unit of fossil fuel consumption (\$/MJ).

- $\beta$ Environmental costs per unit of GHG emissions $(\$ / \mathrm{kg})$.

- $d_{i j}$ Distance $(\mathrm{km})$ between harvesting site $i$ and biofuel facility $j$.

- $t$ Truck capacity in tonnes. 
- $T_{s b}$ Spring breakup timing when road weight restrictions are in place.

- $T_{b i}$ Time period to build up the on-site inventory from which the biorefinery consumes biomass feedstock during spring breakup.

- $\quad N$ The number of operation days at a biorefinery.

- $n$ The number of operation days that the minimum on-hand inventory can meet.

Based on above model inputs and parameters, the decision variables can be determined as follows.

- $q_{i j}$ Amount (tonne) of biomass shipped from harvesting site $i$ to biofuel facility $j$.

- $\varphi_{j}$ Equals to 1 if a biofuel facility is built at site $j$, and 0 otherwise.

- $s_{j}$ Size (MLPY) of a biofuel facility, if any, to be built at site $j$.

\section{Acknowledgements}

This research was supported by Science Foundation of China University of Petroleum, Beijing (No. 2462014YJRC040 and 2462015YQ0401). This research was also supported through an agreement with the Michigan Economic Development Corporation with funding from the U.S. Department of Energy award DE-EE-0000280.

\section{References}

[1] Greene DL, Plotkin SE. Energy futures for the US transport sector. Energ Policy 2011; 29:1255-1270.

[2] Kumar P, Barrett DM, Delwiche MJ, Stroeve P. Methods for pretreatment of lignocellulosic biomass for efficient hydrolysis and biofuel production. Ind Eng Chem Res 2009;48:37133729.

[3] Zhang F, Johnson DM, Sutherland JW. A GIS-based method for identifying the optimal location for a facility to convert forest biomass to biofuel. Biomass Bioenerg 2011;35(9):3951-3961.

[4] Graham RL, English BC, Noon CE. A Geographic Information System-based modelling system for evaluating the cost of delivered energy crop feedstock. Biomass Bioenerg 2000;18(4):309-329.

[5] Frombo F, Minciardi R, Robba M, Rosso F, Sacile R. Planning forest biomass logistics for energy production: A strategic decision model. Biomass Bioenerg 2009;33(3):372-383.

[6] Haddad MA, Anderson PF. A GIS methodology to identify potential corn stover collection locations. Biomass Bioenerg 2008;32(12):1097-1108.

[7] Zhang F, Johnson DM, Johnson MA. Development of a simulation model of biomass supply chain for biofuel production. Renew Energ 2012;44:380-391.

[8] Sokhansanj S, Kumar A, Turhollow AF. Development and implementation of integrated biomass supply analysis and logistics model (IBSAL), Biomass Bioenerg 2006;30:538-547.

[9] Kumar A, Sokhansanj S. Switchgrass delivery to a biorefinery using integrated biomass supply analysis and logistics (IBSAL) mode. Bioresource Technol 2007;98:1033-1044.

[10] Nilsson D. SHAM — a simulation model for designing straw fuel delivery systems. Part 1: model description. Biomass Bioenerg 1999;16 (1):25-38. 
[11] Nilsson D. SHAM - a simulation model for designing straw fuel delivery systems. Part 2: model applications. Biomass Bioenerg 1999;16 (1):39-50.

[12] Huang Y, Chen CW, Fan Y. Multistage optimisation of the supply chains of biofuels. Transport Res E-Log 2010;46(6):820-830.

[13] Eksioglu SD, Acharya A, Leightley LE, Arora S. Analyzing the design and management of biomass-to-biorefinery supply chain. Comput Ind Eng 2009;57:1342-1352.

[14] An H, Wilhelm WE, Searcy SW. A mathematical model to design a lignocellulosic biofuel supply chain system with a case study based on a region in Central Texas. Bioresource Technol 2011;102(17):7860-7870.

[15] Marvin AW, Schmidt LD, Benjaafar S, Tiffany DG, Daoutidis P. Economic optimisation of a lignocellulosic biomass-to-ethanol supply chain. Chem Eng Sci 2012;67(1):68-79.

[16] Kaylen M, Van Dyne DL, Choi YS, Blasé M. Economic feasibility of producing ethanol from lignocellulosic feedstocks. Bioresource Technol 2000;72(1):19-32.

[17] Parker N, Tittmann P, Hart Q, Nelson R, Skog K, Schmidt A, Gray E, Jenkins B. Development of a biorefinery optimized biofuel supply curve for the Western United States. Biomass Bioenerg 2010;34(11):1597-1607.

[18] Walther G, Schatka A, Spengler TS. Design of regional production networks for second generation synthetic bio-fuel - A case study in Northern Germany, Eur J Oper Res 2012; 218(1):280-292.

[19] Dekker R, Bloemhof J, Mallidis I. Operations Research for green logistics - An overview of aspects, issues, contributions and challenges, Eur J Oper Res 2012;219(3):671-679.

[20] Elia JA, Baliban RC, Xiao X, Floudas CA. Optimal energy supply network determination and life cycle analysis for hybrid coal, biomass, and natural gas to liquid (CBGTL) plants using carbon-based hydrogen production. Comput Chem Eng 2011;35:1399-1430.

[21] Leduc S, Starfelt F, Dotzauer E, Kindermann G, McCallum I, Obersteiner M, Lundgren J. Optimal location of lignocellulosic ethanol refineries with polygeneration in Sweden. Energy 2010;35(6):2709-2716.

[22] De Mol RM, Jogems MAH, VanBeek P, Gigler JK. Simulation and optimisation of the logistics of biomass fuel collection. Neth J Agr Sci 1997;45:219-228.

[23] Lin H. Analysis of spring break-up and its effects on a biomass feedstock supply chain in northern Michigan. Master thesis. Michigan Technological University, Houghton, MI. 2012.

[24] Wilson BS. Modelling Cellulosic Ethanol Plant Location Using GIS. Masters Theses. University of Tennessee - Knoxville. 2009.

[25] Zhang F, Johnson DM, Johnson MA, Sutherland JW. Development of a Biomass Supply Chain for Biofuel Production. Industrial Engineering Research Conference, Reno, Nevada. 2011.

[26] Jenkins TL. Size and Location Decision Making for a Biofuel Facility based on Cradleto-Gate Costs, Biomass Resources, and Infrastructure. PhD proposal. Dept. of Mechanical Engineering -Engineering Mechanics, Michigan Technological University. 2009. 
http://www.mendeley.com/research/understanding-national-administrative-cultures-impactupon-administrative-reform-neoinstitutional-model-analysis/

[27] Forest Inventory and Analysis. FIA standard reports. Available from: http://fiatools.fs.fed.us/fido/standardrpt.html; 2009.

[28] Shivan GC, Mueller LS, Potter-Witter K. Michigan Woody Biomass Supply Snapshot. Michigan State University, Department of Forestry. Available from: http://www.michiganforestbiofuels.org/sites/default/files/michigan-woody-biomass-supplysnapshot.pdf; 2011.

[29] MI Geographic Data Library. Available from: http://www.mcgi.state.mi.us/mgdl; 2002.

[30] Miles PD. Forest Inventory EVALIDator web-application version 4.01. St. Paul, MN: U.S. Department of Agriculture, Forest Service, Northern Research Station. EVALID=260903; downloaded 03 March 2011, http://fiatools.fs.fed.us/Evalidator401/tmattribute.jsp.

[31] Frontier Renewable Resources. Available from: http://www.frontierrenewable.com/press/; 2012.

[32] Prentiss \& Carlisle Management Company. Michigan Timber Market Analysis, Prepared for Michigan Department of Natural Resources. Available from: http://michigansaf.org/forestinfo/Market-2008.pdf; 2008.

[33] U.S. Energy Information Administration. PETROLEUM \& OTHER LIQUIDS - Gasoline and Diesel Fuel Update. Available from: http://www.eia.gov/petroleum/gasdiesel/; 2013.

[34] Zhang F, Handler R, Johnson DM, and Shonnard DR. Comparative Analysis of Life Cycle Greenhouse Gas Emissions of Supply Chains for Biofuel and Fossil Fuel Production. 22nd Annual POMS Conference, Reno, Nevada. 2011.

[35] Steen B. A systematic approach to environmental priority strategies in product development (EPS). Version 2000 - models and data of the default method. CPM report 1999:5. Chalmers University of Technology, Environmental Systems Analysis. 1999.

[36] Nguyen TLT, Gheewala SH. Fossil energy, environmental and cost performance of ethanol in Thailand. J Clean Prod 2008;16:1814-1821.

[37] X-RATES. [Internet]. Available from: http://www.Xrates.com/average/?from $=$ EUR\&to $=U S D \&$ amount $=1.00 \&$ year $=2007 ; 2012$.

[38] Johnson DM, Zhang F, Johnson MA. Forestry Biofuel Statewide Collaboration Center (FBSCC) Task B4 Final Report. Michigan Technological University. 2011.

[39] Aden A, Ruth M, Ibsen K, Jechura J, Neeves K, Sheehan J, Wallace B, Montague L, Slayton A, Lukas J. Lignocellulosic Biomass to Ethanol Process Design and Economics Utilizing Co-Current Dilute. Acid Prehydrolysis and Enzymatic Hydrolysis for Corn Stover NREL Technical Report, National Renewable Energy Laboratory. 2002; 154pp.

[40] Michigan State Police. That Time of Year Again: Lighten the Load Spring-Like Weather Brings on Weight Restrictions for Roads. Available from: http://www.michigan.gov/msp/0,1607,7-123-1586_1710-87560--,00.html; 2004. 
Table 1 Summary of input data

\begin{tabular}{|c|c|c|c|}
\hline Model Input & Notation & Value & Data Source \\
\hline Unit stumpage cost & $\mathrm{s}$ & $\$ 10.36 /$ tonne & \multirow{2}{*}{$\begin{array}{l}\text { Prentiss ... } 2008 \\
{[32]}\end{array}$} \\
\hline $\begin{array}{l}\text { Unit harvesting/forwarding } \\
\text { cost }\end{array}$ & $\mathrm{h}$ & $\$ 15.44 /$ tonne & \\
\hline Loading and unloading cost & $\mathrm{t}_{\text {lu }}$ & $\$ 4.10 /$ tonne & \multirow{2}{*}{ Zhang et al. 2012 [7] } \\
\hline Variable mileage cost & $t_{d}$ & $\$ 0.051 /$ tonne-km & \\
\hline Unit inventory holding cost & $\mathrm{H}$ & $\begin{array}{l}\text { \$4.44/tonne-week } \\
\$ 230.88 / \text { tonne-year }\end{array}$ & $\begin{array}{l}\text { Eksioglu et al. } 2009 \\
{[13]}\end{array}$ \\
\hline Unit energy consumption cost & $\alpha$ & $\$ 0.0225 / \mathrm{MJ}$ & EIA 2013 [33] \\
\hline Unit environmental costs & $\beta$ & $\$ 0.144 / \mathrm{kg}$ & X-RATES 2012 [37] \\
\hline
\end{tabular}


Table 2 Data for harvesting/forwarding and transportation [34]

\begin{tabular}{|l|l|l|}
\hline Item & Harvesting/Forwarding & Transportation \\
\hline Energy Demand & $160 \mathrm{MJ} /$ tonne & $1.15 \mathrm{MJ} /$ tonne-km \\
\hline GHG emissions & $12.79 \mathrm{~kg} \mathrm{CO} \mathrm{e}_{2} \mathrm{e} /$ tonne & $0.119 \mathrm{~kg} \mathrm{CO} \mathrm{CO}_{2} \mathrm{e} /$ tonne-km \\
\hline
\end{tabular}


Table 3 Numbers of truckloads for different facility sizes in different time periods

\begin{tabular}{|l|c|c|c|}
\hline \multirow{2}{*}{ Time period } & \multicolumn{3}{|c|}{ Truckloads per day } \\
\cline { 2 - 4 } & 114 MLPY & 151 MLPY & 189 MLPY \\
\hline Nov 1 $1^{\text {st }}$-end of Feb (build up inventory) & 90 & 120 & 150 \\
\hline March $1^{\text {st }}$-April $30^{\text {th }}$ (spring breakup) & 0 & 0 & 0 \\
\hline May $1^{\text {st }}$-Oct $15^{\text {th }} / 16^{\text {th }}$ (regular months) & 60 & 80 & 100 \\
\hline
\end{tabular}


Table 4 Ten most optimal suppliers (counties) for supporting the Clare, MI plant of 189 MLPY

\begin{tabular}{|l|c|c|}
\hline Supplier & Transportation Distance $(\mathrm{km})$ & Amount of Biomass (tonnes) \\
\hline Clare & 24.75 & 140,083 \\
\hline Isabella & 27.01 & 144,524 \\
\hline Gladwin & 48.73 & 143,353 \\
\hline Midland & 50.13 & 146,877 \\
\hline Osceola & 62.84 & 111,097 \\
\hline Mecosta & 65.98 & 190,594 \\
\hline Roscommon & 68.16 & 75,972 \\
\hline Gratiot & 72.97 & 106,937 \\
\hline Bay & 74.57 & 26,730 \\
\hline Missaukee & 83.56 & 47,582 \\
\hline
\end{tabular}


Table 5 Total cost (\$) and average cost (\$/tonne) for different facility locations and plant sizes

\begin{tabular}{|c|c|c|c|c|c|c|}
\hline \multirow{2}{*}{$\begin{array}{c}\text { Biofuel } \\
\text { Facility }\end{array}$} & $\begin{array}{c}\text { Total cost } \\
(\$)\end{array}$ & $\begin{array}{c}\text { Avg. cost } \\
(\$ / \text { tonne })\end{array}$ & $\begin{array}{c}\text { Total cost } \\
(\$)\end{array}$ & $\begin{array}{c}\text { Avg. cost } \\
(\$ / \text { tonne })\end{array}$ & $\begin{array}{c}\text { Total cost } \\
(\$)\end{array}$ & $\begin{array}{c}\text { Avg. cost } \\
(\$ / \text { tonne })\end{array}$ \\
\hline Manton & $37,630,234$ & 55.32 & $51,114,097$ & 56.36 & $65,018,000$ & 57.35 \\
\hline Roscommon & $38,623,709$ & 56.78 & $52,175,823$ & 57.53 & $65,765,242$ & 58.01 \\
\hline Kingsley & $37,864,828$ & 55.66 & $51,672,606$ & 56.97 & $65,878,631$ & 58.11 \\
\hline Kalkaska & $37,752,041$ & 55.50 & $51,813,211$ & 57.13 & $66,045,512$ & 58.25 \\
\hline Gaylord & $36,868,235$ & 54.20 & $50,474,101$ & 55.65 & $64,439,825$ & 56.84 \\
\hline Clare & $38,349,339$ & 56.38 & $52,170,381$ & 57.52 & $66,339,538$ & 58.51 \\
\hline West Branch & $38,337,296$ & 56.36 & $52,069,271$ & 57.41 & $66,296,391$ & 58.48 \\
\hline Traverse City & $38,504,892$ & 56.60 & $52,806,530$ & 58.22 & $67,456,296$ & 59.50 \\
\hline Boyne City & $38,788,143$ & 57.02 & $52,590,862$ & 57.98 & $67,233,865$ & 59.30 \\
\hline
\end{tabular}


Table 6 Optimal facility locations and sizes for base case

\begin{tabular}{|c|c|c|c|c|c|c|}
\hline Biofuel Facility & \multicolumn{7}{|c|}{ Facility Size (MLPY) } \\
\hline Manton & 0 & 132 & 114 & 114 & 177 & 189 \\
\hline Roscommon & 0 & 0 & 0 & 0 & 114 & 149 \\
\hline Kingsley & 0 & 0 & 0 & 114 & 114 & 189 \\
\hline Kalkaska & 0 & 0 & 114 & 0 & 0 & 0 \\
\hline Gaylord & 189 & 114 & 114 & 114 & 114 & 116 \\
\hline Clare & 0 & 0 & 114 & 133 & 189 & 189 \\
\hline West Branch & 0 & 133 & 114 & 169 & 125 & 189 \\
\hline Traverse City & 0 & 0 & 0 & 0 & 0 & 0 \\
\hline $\begin{array}{c}\text { Boyne City } \\
\text { Total Demand } \\
\text { (MLPY) }\end{array}$ & 0 & 0 & 0 & 114 & 114 & 114 \\
\hline
\end{tabular}


Table 7 Comparison results for the multi-location problem

\begin{tabular}{|l|c|c|c|c|c|}
\hline Demand (MLPY) & 379 & 570 & 758 & 947 & 1,135 \\
\hline Delivered feedstock cost (million \$) & 76.5 & 116.0 & 159.4 & 208.4 & 264.4 \\
\hline Inventory holding cost (million \$) & 30.1 & 45.1 & 60.2 & 75.2 & 90.3 \\
\hline Energy cost (million \$) & 12.6 & 19.5 & 28.4 & 40.2 & 55.5 \\
\hline Emissions cost (million \$) & 7.1 & 11.0 & 16.2 & 23.3 & 32.7 \\
\hline Overall cost (million \$) & 126.3 & 191.7 & 264.3 & 347.1 & 442.9 \\
\hline Average cost (\$/tonne) & 55.7 & 56.4 & 58.3 & 61.2 & 65.1 \\
\hline Average transportation distance (km) & 37.9 & 41.6 & 51.8 & 67.7 & 88.4 \\
\hline
\end{tabular}


Table 8 Comparison results for single location problem

\begin{tabular}{|l|c|c|c|c|}
\hline Demand (MLPY) & 379 & 570 & 758 & 947 \\
\hline Delivered feedstock cost (million \$) & 83.7 & 131.4 & 182.8 & 239.5 \\
\hline Inventory holding cost (million \$) & 30.1 & 45.1 & 60.2 & 75.2 \\
\hline Energy cost (million \$) & 16.3 & 27.4 & 40.4 & 56.1 \\
\hline Emissions cost (million \$) & 9.4 & 16.1 & 24.0 & 33.6 \\
\hline Overall cost (million \$) & 139.5 & 220.0 & 307.3 & 404.5 \\
\hline Average cost (\$/tonne) & 61.5 & 64.7 & 67.8 & 71.4 \\
\hline Average transportation distance (km) & 69.2 & 86.2 & 102.7 & 121.9 \\
\hline
\end{tabular}




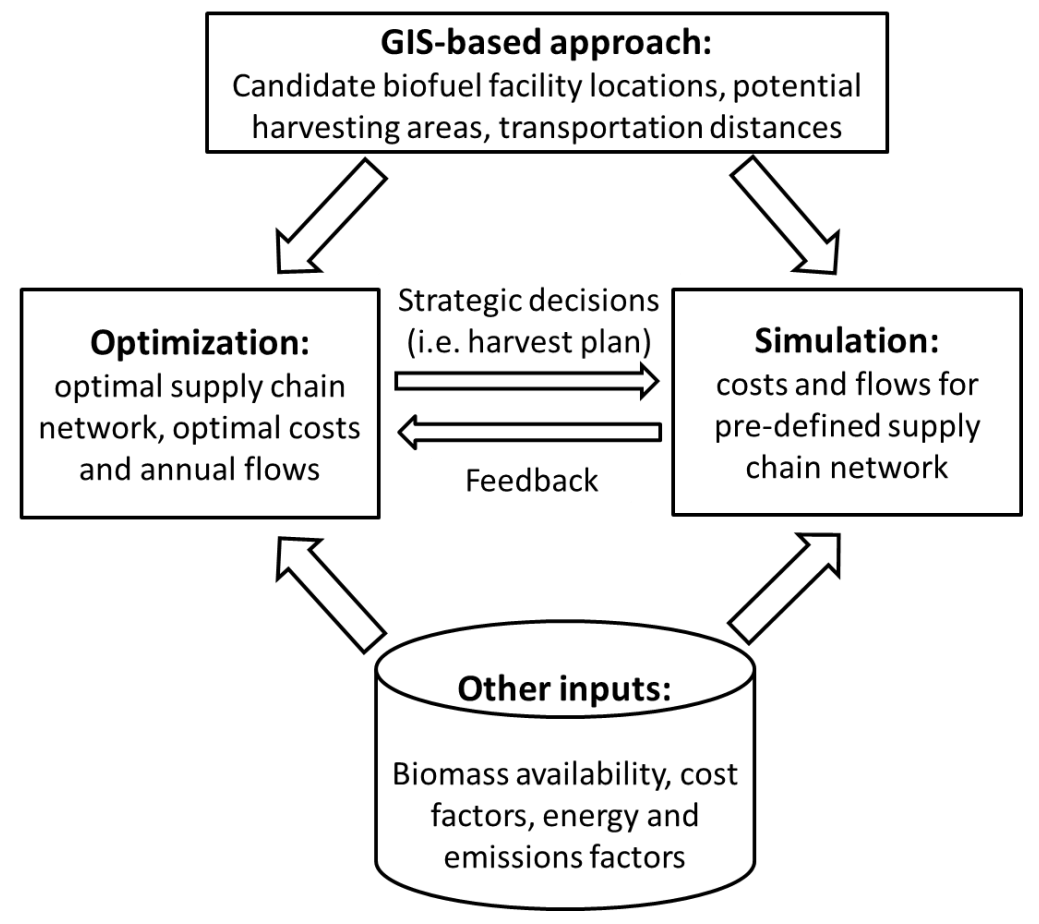

Fig. 1 Overview of the Integrated Methodology 

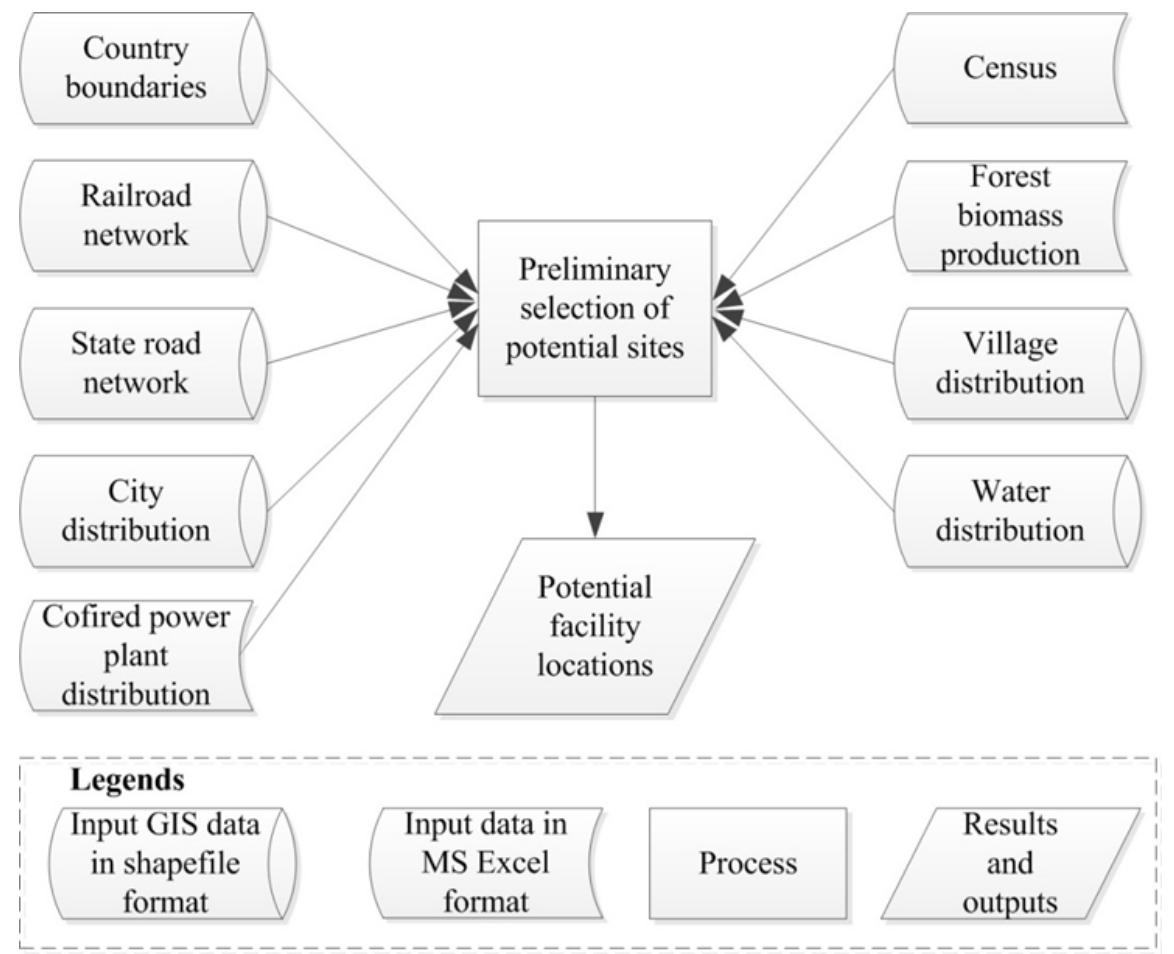

Fig. 2 Overview of the GIS-based methodology 


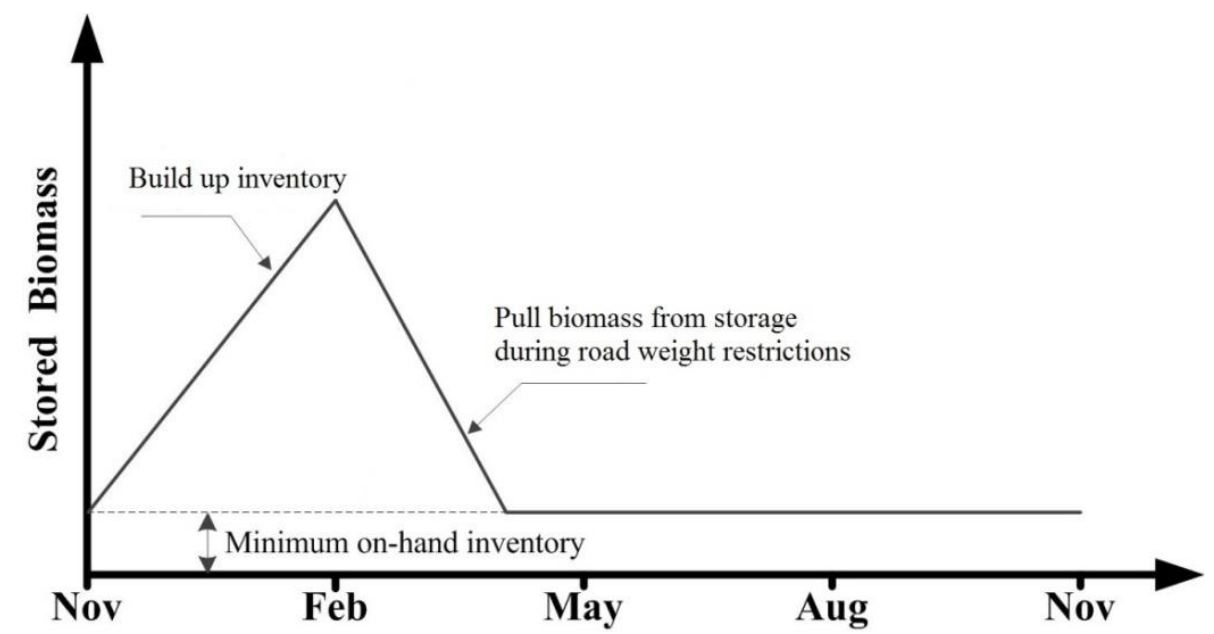

Fig. 3 One Possible Scenario for Biomass Storage as a Function of Time 


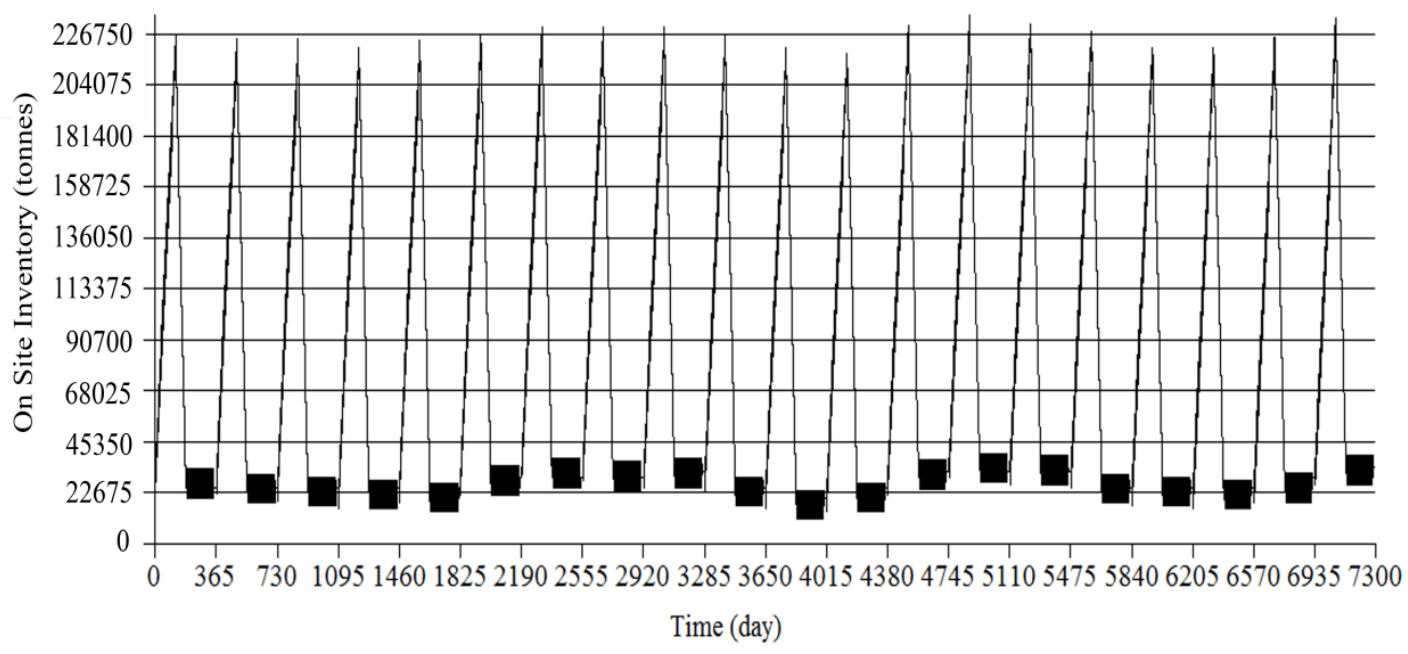

Fig. 4 Inventory level for a 189-MLPY biorefinery in Clare, MI operating 20 years 


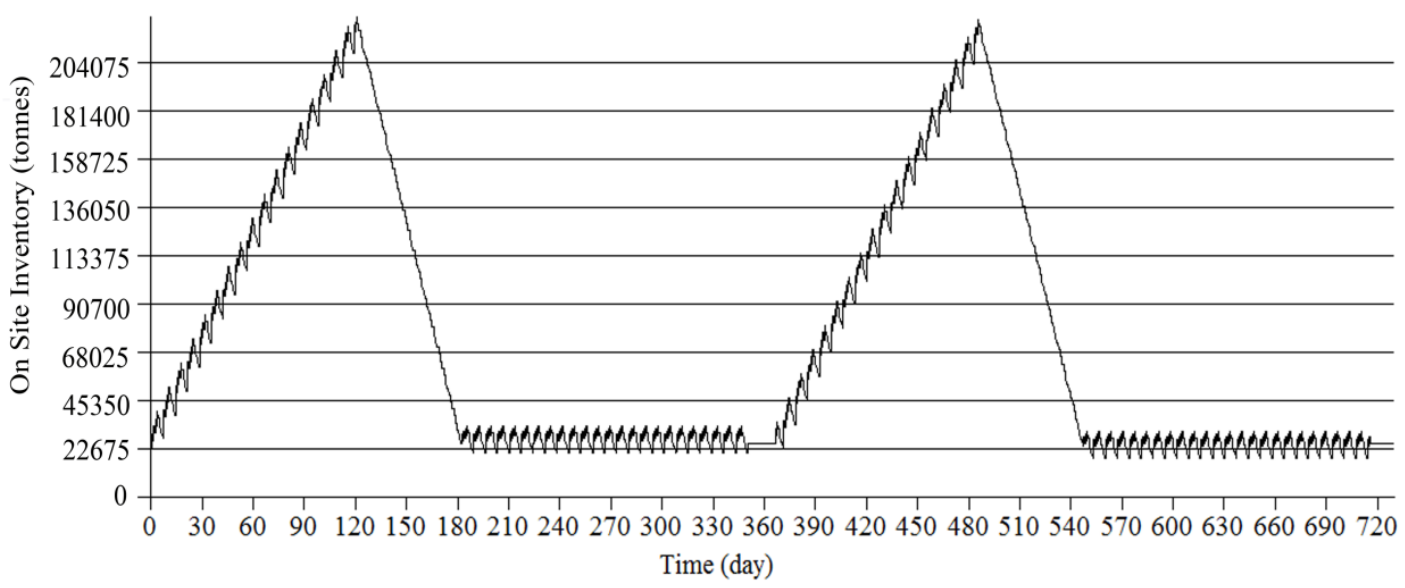

Fig. 5 Inventory level for the first two years' operation 